http://dx.doi.org/10.18675/1981-8106.vol26.n51.p64-78

\title{
Verdade, mentira ou apenas um caso de poesia? A produção imaginária cultivada na escola
}

\author{
Truth, lie or just a case of poetry? The imaginary production cultivated in \\ school
}
¿Verdad, mentira o apenas un caso de poesía? La producción imaginaria cultivada en la escuela

\author{
Rita de Cássia Cristofoleti' \\ Cláudia Beatriz de Castro Nascimento Ometto" \\ 'Universidade Metodista de Piracicaba - (UNIMEP) - São Paulo - Brasil. E-mail: ricacri@uol.com.br \\ "Universidade Estadual de Campinas - (UNICAMP) - São Paulo - Brasil. E-mail: \\ cbometto@yahoo.com.br
}

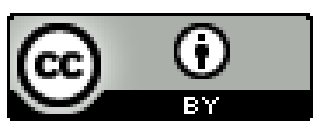

Educação: teoria e prática, Rio Claro, SP, Brasil - eISSN: 1981-8106

Está licenciada sob Licença Creative Common

\section{Resumo}

O objetivo deste artigo é analisar uma prática pedagógica na qual alunos de um quarto ano do Ensino Fundamental viveram um processo criativo mediado pela leitura da literatura procurando compreender até que ponto, a produção imaginária é cultivada na escola. $\mathrm{O}$ referencial teórico adotado foi a perspectiva Histórico-Cultural de desenvolvimento humano que considera que quanto mais rica for a experiência social e cultural da criança, mais possibilidades existirá de criação e de imaginação, portanto, cabe a escola possibilitar meios de desenvolvimento da criação aos seus alunos. O episódio recortado para análise faz parte da coleta de dados de uma das pesquisadoras durante o percurso de mestrado. Metodologicamente, a pesquisa de cunho qualitativo documentou as relações de ensino vividas por uma professora e seus alunos através de audiogravação e anotações em diário de campo. Também foram tomados como dados os planos de ensino da professora e as atividades produzidas pelos alunos. Conclui-se que o ato de criação e o lugar do imaginário como 
condição essencialmente humana, pela mediação da linguagem, pode ter lugar na escola ao mesmo tempo em que as práticas pedagógicas podem constituir-se como novas formas de participação das crianças na cultura.

Palavras-chave: práticas pedagógicas, mediação, linguagem, imaginação, criação.

\begin{abstract}
The objective of this paper is to analyze a pedagogical practice in which students from fourth grade of elementary school lived a creative process mediated by the reading of literature seeking to understand the extent to which the imaginary production is cultivated in school . The theoretical framework adopted was the Cultural-Historical perspective of human development that considers how much richer the social and cultural experience of the child, the more possibilities exist for creation and imagination, so it's up to schools to enable development means creating their students. The episode cut for analysis is part of the collection of data from one of the researchers during the course master. Methodologically, a qualitative research documented the relationships experienced by a school teacher and her students through audiogravação and notes in a field journal. Were also taken as given the plans of the teacher and teaching activities produced by the students. We conclude that the act of creation and the place of the imaginary as essentially human condition, through the mediation of language, can take place at school while teaching practices that may be constituted as new forms of children's participation in culture.
\end{abstract}

Keywords: teaching practices, mediation, language, imagination, creation.

\title{
Resumen
}

El objetivo de este artículo es analizar una práctica pedagógica en la que alumnos de un cuarto año de Enseñanza Primaria vivieron un proceso creativo mediado por la lectura de literatura procurando comprender hasta qué punto se cultiva la producción imaginaria en la escuela. El referencial teórico adoptado fue la perspectiva Histórico-Cultural de desarrollo humano que considera que cuánto más rica es la experiencia social y cultural del niño, más posibilidades de creación y de imaginación existirán; por tanto, cabe a la escuela posibilitar los medios de desarrollo de la creación para sus alumnos. El episodio seleccionado para análisis hace parte de la recolecta de datos de una de las investigadoras durante el transcurso del maestrado. Metodológicamente, la investigación de carácter cualitativo documentó las relaciones de enseñanza vividas por una profesora y sus alumnos a través de audiograbación y anotaciones en un diario de campo. También se tomaron como datos los planes de enseñanza de la profesora y las actividades producidas por los alumnos. Se concluye que el acto de creación y el lugar del imaginario como condición esencialmente 
humana, por la mediación del lenguaje, pueden tener lugar en la escuela, al mismo tiempo en que las prácticas pedagógicas se pueden constituir como nuevas formas de participación de los niños en la cultura.

Palabras clave: prácticas pedagógicas, mediación, lenguaje, imaginación, creación.

\section{Introdução}

Neste texto nos propusemos a tecer algumas reflexões sobre a relação entre o real, o imaginário e o simbólico na perspectiva Histórico-Cultural do desenvolvimento humano procurando compreender o lugar do imaginário na educação. Nesse sentido, nos perguntamos: até que ponto, a produção imaginária é cultivada na escola? Qual o lugar reservado na educação escolar ao imaginário, instância fundante da atividade criadora do homem?

Vigotski compreende a imaginação como uma formação especificamente humana, e destaca a atividade criadora do homem, evidenciando "o papel fundamental da educação e das relações de ensino na apropriação e produção de novas formas de atividade e vida". (2009, p. 07).

Segundo a perspectiva Histórico-Cultural, a tríade Real/Imaginário/Simbólico denominada aqui de "instâncias do ser humano" (PINO, 2006) constitui os três planos de atuação do poder criador do homem. Sendo assim, o que caracteriza o humano é a sua possibilidade de criação. "Chamamos atividade criadora do homem aquela em que se cria algo novo. [...] É exatamente a atividade criadora que faz do homem um ser que se volta para o futuro, erigindo-o e modificando o seu presente". (VIGOTSKI, 2009, p. 13-14). Posto isto, para entendermos a tríade proposta anteriormente, faz-se necessário explicitar o que vem a ser cada uma delas.

Comecemos pelo real natural. O real natural é uma categoria abstrata que representa uma forma de conceber a realidade. O real é o plano da natureza. Nesse sentido, o real natural diz respeito ao mundo das coisas que têm existência em si. (PINO, 2006). Já o real cultural ou real humano (PINO, 2006a) pressupõe transformação. Transformação da natureza pelas mãos humanas. Aqui já podemos falar em processo de criação, visto que segundo Vigotski (2009, p. 14) "necessariamente tudo o que nos cerca e foi feito pelas mãos do homem, todo o mundo da cultura, diferentemente do mundo da natureza, tudo isso é produto da imaginação e da criação humana que nela se baseia".

Por considerarmos o poder de criação humana, podemos dizer que o homem chegou a um ponto da evolução que ultrapassa o limite da própria natureza, na medida em que ele a transforma. Nesse processo de transformação da natureza, o homem torna-se humanizado, cria-se então o mundo humano, o mundo da cultura. 
Sobre o processo de evolução humana, Pino (2010, p. 743), destaca que a "evolução [...] permitiu aos seres humanos, mais do que a todas as outras espécies de organismos, transpor as barreiras da dependência das condições naturais do meio, transformando-o num meio cultural adaptado às suas próprias necessidades". Essa possibilidade, no entanto, não descarta a dependência do meio natural visto que este é o suporte necessário para criar o meio cultural. Cabe ao homem produzir transformações na natureza, ao mesmo tempo em que realiza essas transformações, ele também modifica a sua própria natureza.

"A atividade criadora produz uma espécie de cumplicidade entre a natureza humana e a natureza objeto da sua ação para criar o 'mundo humano', constituído por ambas". (PINO, 2006, p. 54). Assim sendo, ao falar de real natural e real cultural podemos dizer que junto ao nascimento biológico vai sendo constituído o nascimento cultural. O homem nasce homem, mas um segundo nascimento é possível: o nascimento cultural. Ao enfatizar o nascimento cultural do homem, Vigotski (2000, p. 26), no manuscrito de 1929, nos sinaliza que "por trás de todas as funções superiores e suas relações estão relações geneticamente sociais, relações reais das pessoas".

Neste sentido é possível afirmar que as funções culturais surgem quando o homem começa a fazer transformações na natureza, pelo próprio trabalho, que transforma a natureza e ao mesmo tempo se transforma. "As funções superiores diferentemente das inferiores, no seu desenvolvimento, são subordinadas às regularidades históricas”. (VIGOTSKI, 2000, p. 23).

Quando falamos em transformação da natureza, do real pelas mãos humanas, podemos fazer uma ligação muito próxima ao campo do imaginário, pois a imaginação diz respeito a uma formação especificamente humana que envolve transformação e criação.

A primeira forma de relação entre imaginação e realidade consiste no fato de que toda obra da imaginação constrói-se sempre de elementos tomados da realidade e presentes na experiência anterior da pessoa. Seria um milagre se a imaginação inventasse do nada ou tivesse outras fontes para suas criações que não a experiência anterior. Somente as representações religiosas e místicas sobre a natureza humana atribuem a origem das obras da fantasia a uma força estranha, sobrenatural, e não a nossa experiência. (VIGOTSKI, 2009, p. 20).

Nesse contexto, a experiência que temos com o mundo e a vivência com outros humanos nos possibilitam espaços para criação e para a invenção do novo. Esse aspecto se torna essencial quando discutimos o papel da escola, passemos a ele.

\section{O imaginário, o processo de criação e o papel da escola}


Uma das preocupações centrais da obra de Vigotski (2009) dizia respeito ao lugar do imaginário e das condições de ensino que possibilitassem às crianças novas formas de criação, destacando a fundamental importância do trabalho pedagógico e da abertura de novas formas de participação das crianças na cultura. Portanto, o desafio da escola, nessa forma de pensar as relações de ensino, está em formar pessoas criadoras. A infância, segundo Vigotski (1998) é o lugar da produção imaginária e essa capacidade não deve ser podada na escola. "A imaginação é um processo psicológico novo para a criança; representa uma forma especificamente humana de atividade consciente, não está presente na consciência de crianças muito pequenas e está totalmente ausente em animais”. (VIGOTSKI, 1998, p. 122).

Nesse contexto, as brincadeiras de faz-de-conta representam exemplos da mais autêntica e verdadeira criação, visto que "a brincadeira da criança não é uma simples recordação do que vivenciou, mas uma reelaboração criativa de impressões vivenciadas". (VIGOTSKI, 2009, p. 17). Essa consideração vigotskiana destaca, portanto, a importância do brincar como possibilidade de desenvolvimento dos processos psíquicos, quer seja nas relações diretas ou indiretas destas atividades. Segundo Lima (1992, p. 19), destacam-se em dois grupos as partes que integram esses processos, a saber, "do primeiro grupo fazem parte a imaginação, a linguagem e o pensamento; do segundo, a memória”.

Nessa relação entre imaginação e atividade criadora na escola, Vigotski (2009) destaca o importante papel que tem o professor e as condições sociais de produção de ensino e de acesso às formas culturais que são possibilitadas às crianças. Quanto mais rica for a experiência social e cultural da criança, mais possibilidades essa criança terá de criação e de imaginação. Nesse aspecto, a experiência social faz a diferença. Por isso, a escola deve possibilitar meios e conhecimentos de desenvolvimento da criação para todos os alunos, independente da classe social e econômica dos mesmos, uma vez que "[...] a atividade criadora da imaginação depende diretamente da riqueza e da diversidade da experiência anterior da pessoa, porque essa experiência constitui o material com que se criam as construções da fantasia”. (VIGOTSKI, 2009, p. 22).

A compreensão de que o espaço escolar e o trabalho pedagógico são essenciais ao desenvolvimento intelectual das pessoas sustenta uma prática de ensino entendida como possibilidade de articulação entre o passado e o futuro no processo de elaboração acerca do presente. Nessa concepção há espaços e condição para se criar o novo. A tarefa do educador é, portanto, oferecer ao aluno o novo, para partilhar do mundo. A "novidade" do novo é a esperança do velho, que perdeu a sensibilidade em virtude da familiaridade com o mundo. $\mathrm{O}$ novo reanima o velho, por mostrar a novidade.

Pela linguagem nos desprendemos dos aspectos físicos, próprios do mundo, do real natural, transcendendo àquilo que apenas nossos sentidos nos permitem. $\mathrm{O}$ mundo humano vai além daquilo que existe à nossa volta e que é acessível aos nossos sentidos; ao contrário, o mundo humano é um mundo simbólico, o mundo da palavra. 
Posso pensar no que fiz ontem e planejar o que farei amanhã. Tenho consciência do tempo: de um passado, um presente e um futuro. Isto é possível pela palavra, que me representa o ontem, o hoje e o amanhã. Enquanto o animal só possui o seu presente: está aderido a um hoje eterno. (DUARTE JÚNIOR, 1991, p.17)

O que possibilita ao homem uma vida qualitativamente diferente de todas as demais formas de vida é a consciência, produto de sua capacidade simbólica, de sua palavra. Segundo Duarte Júnior (1991) o mundo é modificado pelo o homem, a medida que dá sentido à suas ações visando o futuro, planejando, pensando, e só então, agindo. Essa ação é a construção das possibilidades do antes imaginado. Segundo o autor, somente o mundo humano é capaz de suplantar a simples dimensão física - o real natural entendido como possibilidade de um vir a ser real cultural, ou seja, um mundo também simbólico.

Este processo é vivido e significado pela linguagem, uma vez que esta possibilita a ordenação do mundo num todo significativo. Com ela organiza-se o real natural, atribuindolhe significados. Todas as sensações e percepções são significadas pela linguagem humana, produzindo sentidos diversos.

Nesse sentido, a educação deve ser entendida como acesso ao conhecimento e não como imposição ao conhecimento. Devemos pensar em não fazer da escola somente o espaço da reprodução. Adquirir conhecimento significa apropriar-se dos saberes e conhecimento é algo da criação humana.

Quando acompanhamos a história das grandes invenções [...] quase sempre é possível notar que elas surgiram como resultado de uma imensa experiência anterior acumulada. A imaginação origina-se exatamente desse acúmulo de experiência. [...] quanto mais rica é a experiência, mais rica deve ser também a imaginação. (VIGOTSKI, 2009, p. 22).

"A conclusão pedagógica a que se pode chegar com base nisso consiste na afirmação da necessidade de se ampliar a experiência da criança, caso se queira criar bases suficientemente sólidas para a sua atividade de criação". (VIGOTSKI, 2009, p. 23).

Partindo desse pressuposto, podemos afirmar que só o humano pode criar o novo, o inexistente. E é a partir da capacidade humana de imaginar o inexistente a partir do existente que é possível fazer o inexistente, um dia existir. Essa capacidade de pensamento, de planejamento, de imaginação e de criação, é a possibilidade humana de transformação da realidade, de produção cultural. 
A história de toda humanidade só se torna possível com a transmissão do conhecimento produzido para as novas gerações, portanto, o movimento da historicidade, das aquisições da cultura de um povo, depende também, das relações educativas. Daí a importância de defendermos o espaço da escola como um espaço que deve ser rico de experiências culturais e, se estamos falando de criação, um espaço de orientação dos sentidos, de "refinamento de um grau de sensibilidade às coisas que a cultura é capaz de dar". (PINO, 2006, p. 67).

\section{Mentiras poéticas}

Aprendi com meu filho de dez anos

Que a poesia é uma descoberta

Das coisas que nunca vi.

(ANDRADE apud ABRAMOVICH, 1994)

A atividade que apresentaremos partiu de um trabalho realizado em uma sala de aula de alunos que frequentavam uma terceira série - hoje quarto ano do Ensino Fundamental - de uma escola particular situada em uma cidade do interior paulista ${ }^{1}$. Os alunos, oriundos de famílias com um elevado capital cultural, encontravam-se na faixa etária de 9 anos de idade.

Metodologicamente, a pesquisa ancorou-se na abordagem histórico-cultural do desenvolvimento humano de Vigotski, a qual destaca a centralidade da linguagem e do outro na constituição da subjetividade humana, nesse sentido, o foco do olhar da pesquisadora em sala de aula voltou-se para a compreensão da dinâmica interativa entre professora-alunos no decorrer de um ano letivo. Trata-se, portanto, de uma pesquisa de cunho qualitativo, descritivo e analítico que como procedimento de produção dos dados realizou audiogravação e transcrição das aulas como também anotações em diário de campo. Também foram tomados como dados os planos de ensino da professora e as atividades produzidas pelos alunos.

No que diz respeito ao material empírico utilizado para a produção deste artigo, os dados foram produzidos no decorrer de um bimestre letivo, sendo que o objetivo inicial da professora relacionava-se ao trabalho com a leitura e a escrita. No entanto, no decorrer da atividade, foram abertas possibilidades de proposição de uma atividade criativa, que o grupo denominou, posteriormente, de Mentiras Poéticas.

\footnotetext{
${ }^{1}$ Os dados produzidos e não utilizados na dissertação de uma das autoras começaram a ser utilizados para análise apenas em 2012, quando passamos a realizar um projeto de pesquisa mais amplo preocupado em compreender as atividades de leitura e de escrita envolvidas na articulação que se processa entre as escolhas relativas aos modos de organização e de circulação dessas práticas, pelos professores, com as réplicas ativas produzidas pelos alunos.
} 
Para instaurar a atividade a professora leu com as crianças o conto "A incapacidade de ser verdadeiro", de Carlos Drummond de Andrade. É um conto curto, do livro "Contos Plausíveis", porém muito comovente, no qual a trama gira em torno de Paulo, um menino com fama de mentiroso. Na tentativa de que a criança deixasse de contar suas mentiras sua mãe colocou-lhe várias vezes de castigo, o que de nada resolveu, até que chegou a ser examinado por um médico para descobrir, de fato, de qual mal ele padecia. O médico, após examiná-lo, conclui que não havia nada a fazer, pois "esse menino é mesmo um caso de poesia" (ANDRADE, 2003, p. 19).

Após a realização da leitura, o grupo iniciou uma discussão sobre o texto, propriamente dito, porém, no decorrer da discussão as crianças começaram a indagar a postura da mãe de Paulo ao colocá-lo de castigo por tão pequeno "delito" ${ }^{2}$. Sugeriram que, ao invés de privar a criança do futebol, a mãe poderia conversar com ela sobre algumas questões, que nós, pesquisadoras, identificamos estarem em elaboração pelas crianças: os conceitos de verdade e de mentira. A professora "embarcou" na discussão proposta pelas crianças e no decorrer da discussão foi possível perceber a dicotomia entre o bem e o mal, a verdade e a mentira. As crianças iam evidenciando que o bem e a verdade estão de um lado. O mal e a mentira estão de outro. Nesse sentido, o texto lido colocou-se como parte de um discurso social no contexto da cultura na qual estamos inseridos.

Na sequência de aulas, após interlocuções com a professora, que assumiu efetivamente o lugar de mediadora do processo, uma vez que trabalhou com os sentidos em circulação na sala de aula, a pauta das discussões esteve relacionada a três questões provocadoras: "O que é a verdade?"; "O que é a mentira?" e "Quando podemos considerar que alguém está mentindo?" Essa discussão possibilitaria às crianças a elaboração dos significados e sentidos atribuídos, socialmente, aos conceitos abordados no texto.

Das perguntas iniciais as crianças foram trazendo suas experiências para a sala de aula, experiências que provocaram inúmeras reflexões, a ponto de considerarem que "Paulo não era mentiroso, ele apenas tinha a mente fértil", pois "mentira só é mentira quando alguém faz com intenção de prejudicar o outro", mas "tem gente que mente para ajudar, para não magoar...".

"Paulo não, ele não estava ajudando nem prejudicando ninguém”, ele só estava "colocando para fora a sua imaginação" e, por este motivo, "Dona Coló não precisaria colocar o filho de castigo pelas coisas que ele falava", "ela poderia conversar com ele, dar a ele um caderno de anotações", "assim, quem sabe, um dia ele poderia vir a ser um grande poeta".

"É verdade, o Dr. Epaminondas estava certo", "Paulo inventava muito mais poesia do que mentira...". "Eram mentirinhas porque não eram verdade, mas eram

\footnotetext{
${ }^{2}$ Os enunciados das crianças estarão destacados no texto em itálico, entre aspas.
} 
poéticas!" "Assim, como se disséssemos que vimos um elefante no centro da cidade passeando de coleira com seu dono...".

Trabalhar ao mesmo tempo com diversas poesias de assuntos de interesse dos alunos contribui para a compreensão dos textos de modo que, ao abordarem o mesmo assunto, de formas diferentes, são abertas possibilidades para que cada um se encontre em uma das possíveis leituras sobre o assunto, o que subsidia a ampliação de discussões, interesses e conhecimentos acerca dos mais variados temas. Duarte Júnior (1991), ao tratar da temática arte-educação, ensina-nos que ainda que os assuntos de diferentes poemas sejam paralelos e parecidos, os diferentes autores os tratam de diferentes formas, e estes, por sua vez, serão valorizados por seus leitores por ângulos diferenciados.

Ainda que todos esses pressupostos não estivessem explícitos para a professora, para alimentar a discussão, ela levou para a sala de aula um outro texto que abordava a mesma temática, um texto de Manoel de Barros intitulado "O menino que carregava água na peneira", do livro "Exercícios de ser criança" (1999), considerando que o título inusitado já reportaria as crianças ao impossível, ao caráter lúdico, ao maravilhoso. Um texto poético que tem como tema a infância, momento em que tanto a criatividade quanto a liberdade manifestam-se de modo bastante explícito. Ao contrário da mãe de Paulo, a mãe deste menino compreendia suas atitudes poéticas e seu mundo de sonho e imaginação, apoiando suas aventuras imaginativas.

Ao discutir este segundo texto, os alunos foram cotejando-o ao anterior, uma vez que foram capazes de identificar a temática e estabelecer relações entre os conteúdos. $\mathrm{Na}$ dinâmica discursiva da sala de aula a professora foi mediando e (entre)tecendo os enunciados das crianças, procurando evidenciar que tanto nas "mentiras" de Paulo, quanto nas do menino que carregava água na peneira, o que as tornava poéticas estava relacionando a algo do real, verossímil, passível de acontecimento em relação com algo não real, inverossímil, impossível de acontecer.

Assim, no movimento dialógico, no acontecimento mesmo da aula, nasceu a proposta do trabalho: "por que não experimentamos inventar algumas 'mentirinhas', tia? Depois, podemos ilustrar na aula de informática!".

Eis algumas delas:

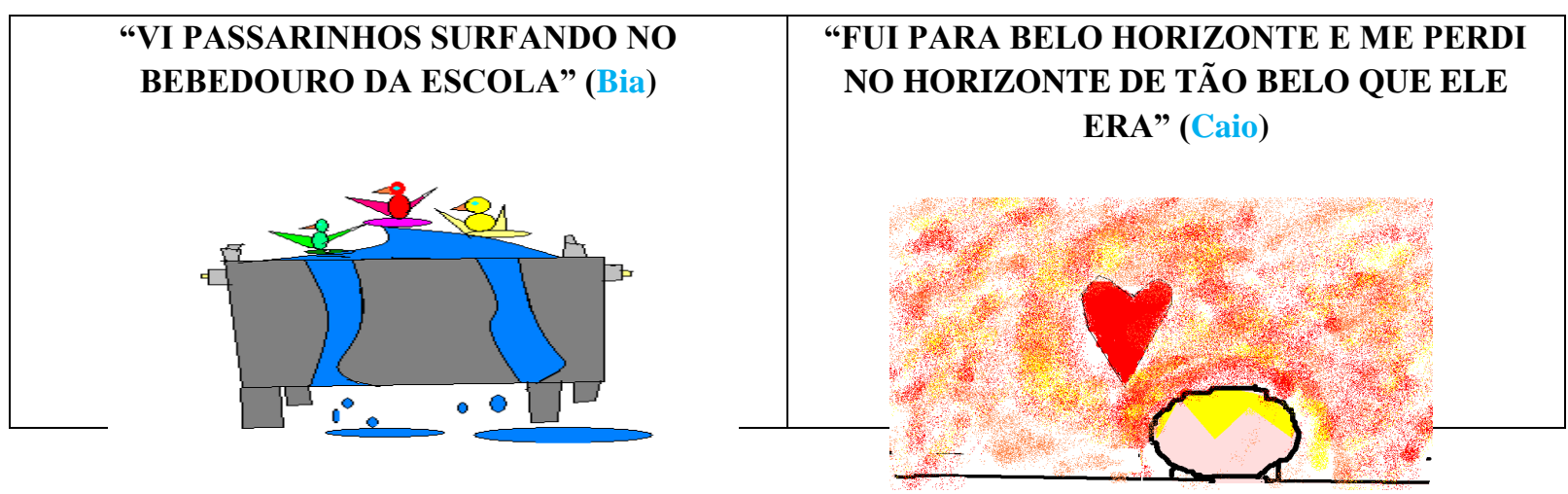

Educação: Teoria e Prática/ Rio Claro/ Vol. 26, n.51/ p. 64-78/ Jan-Abr. 2016. 


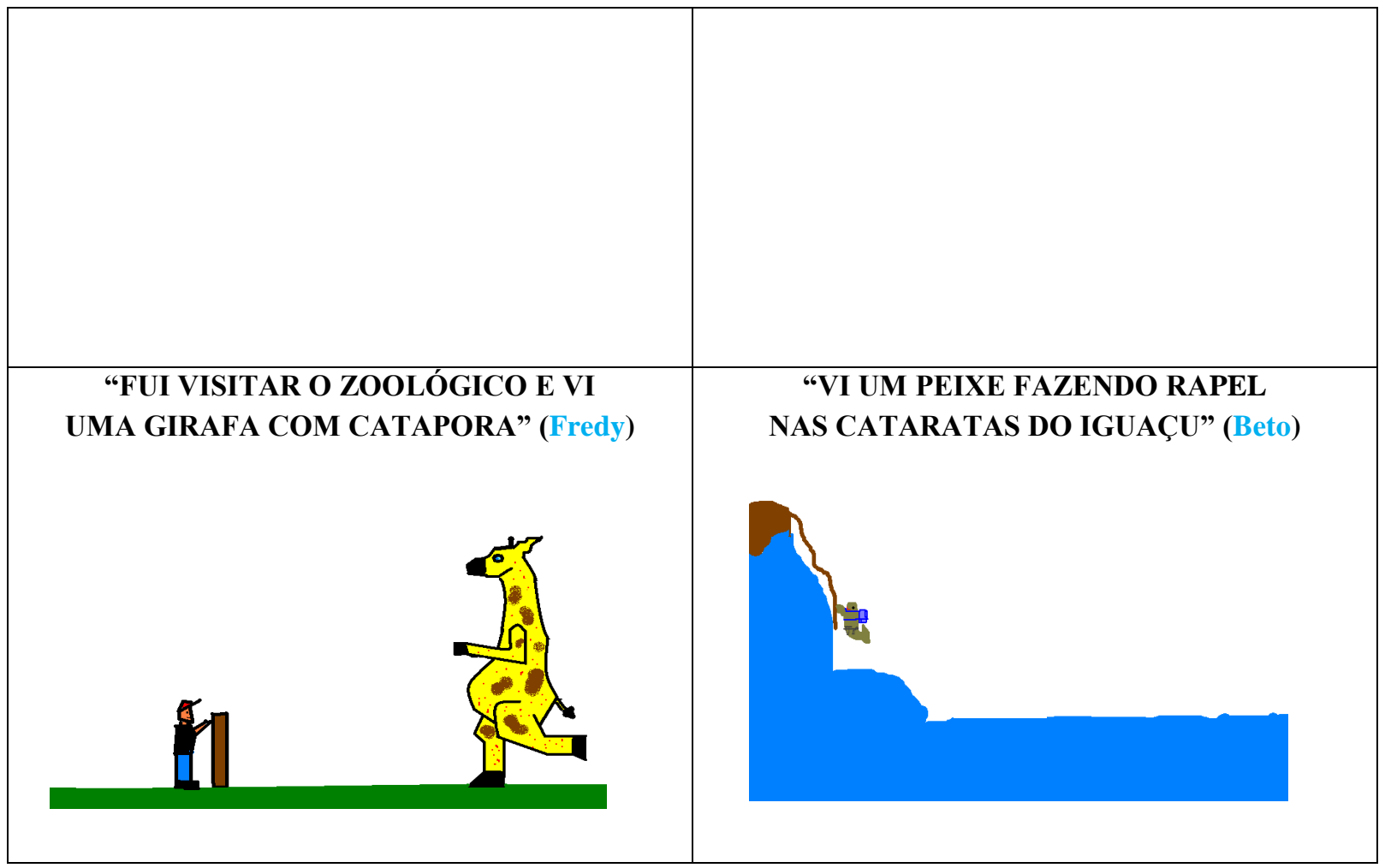

Nos limites deste texto, selecionamos estas quatro produções para inserir no artigo visto que seus autores, ao responderem ao questionamento: por que fez essa mentira poética? Assim as comentaram:

(Bia ${ }^{3}$.) "Ah, eu lembrei que toda vez que vou beber água depois do intervalo o bebedouro está cheio de passarinhos bicando os restos dos lanches [e por que estão surfando?] porque do bebedouro sai água como uma onda do mar!"; (Caio) "Porque minha avó mora em Belo Horizonte e toda vez que eu vou pra lá vejo o por do sol no horizonte, é tão lindo..."; (Fredy) "É que na semana passada fui no zoológico com meus primos e quando vi a girafa lembrei de quando eu tive catapora, fiquei que nem ela"; (Beto) "Ah, peixe não vive na água? Gente não faz rapel? Quando o peixe vai desovar aqui no rio Piracicaba o que que ele faz? Não sobe ao contrário? Então, ele faz rapel!!!"

Ao olhar para os textos produzidos, se tomarmos a concepção de texto tal qual proposta por Bakhtin (2003, p.307), que o define como "qualquer conjunto coerente de signos", o que inclui suas ilustrações, poderemos, em articulação com suas respostas, afirmar que nesta prática educativa escolarizada houve sim lugar para o imaginário. A professora, mediada pelos enunciados das crianças e acatando a proposta do grupo possibilitou espaço para criação. "A primeira coisa a se considerar ao falar do campo do imaginário são as imagens, uma vez que elas constituem o que poderíamos chamar de matéria-prima da atividade imaginária". (PINO, 2006, p. 55).

\footnotetext{
${ }^{3}$ Os nomes são fictícios para resguardar a identidade dos sujeitos.
} 
Segundo Pino (2006a) a imagem pode ser considerada a partir de dois planos diferentes. O primeiro, o plano do natural, que constitui a função natural de perceber. $\mathrm{O}$ segundo, o plano do cultural, que constitui a função humana de perceber (p. 52).

No segundo caso, é o resultado de um complexo processo mental de conversão desses sinais em complexos imagéticos portadores de significação. Isso confere à imagem natural um estatuto novo que, sem perder suas características naturais ou biológicas, faz dela o meio para o homem transpor os limites da materialidade e da singularidade das coisas reais e atingir os espaços da representação simbólica que lhe permite conferir a essas coisas uma dimensão material e generalizadora. (PINO, 2006a, p. $52)$.

Quando a imagem adquire significação, estamos falando de imaginário, de plano cultural. Dada a dimensão humana, que ao mesmo tempo é biológica, mas também é cultural, podemos dizer que "aquilo que denominamos imagem - [...] pode ser ao mesmo tempo, um evento natural, comum a outras espécies, e um evento cultural, exclusivo do humano" (PINO, 2006a, p. 54).

As palavras, por sua vez, são um "resumo fragmentado" do nosso sentir constante. Elas procuram sempre tomar este sentir e simbolizá-lo. Buscam significá-lo e exprimi-lo. A palavra, na sua plasticidade, permitiu aos leitores que se experimentassem em diferentes emoções, posicionando-se com juízos de valor, elaborando relações lógicas, em face de experiências pessoais (OMETTO; CRISTOFOLETI, 2012), uma vez que é pela linguagem que procuramos delimitar e explicar os nossos sentimentos, significá-los. Porém, feito apanhar um punhado de areia na praia, sempre nos escapa algo por entre os dedos. A linguagem não é clara, ela apenas indicia, ensina-nos Bakhtin (2003). A linguagem, que é conceitual e classificatória, apenas aponta e tenta classificar este sentir - que é inclassificável , sem, contudo, poder descrevê-lo.

Nesse processo os alunos viveram uma experiência de significação, de interpretação e de reconhecimento das imagens num dado contexto de significado que possibilitou a criação. Por sua vez, a singularização dos sentidos apreendidos na dinâmica interativa imediata materializou-se em cada uma das "Mentiras Poéticas" indiciando os processos de compreensão dos alunos uma vez que, segundo Bakhtin (2003), compreender é produzir réplicas às ações, gestos e dizeres que se tornam significativos aos sujeitos. Na e pela prática pedagógica vivida, pela mediação da linguagem, as crianças aproximaram-se muito de uma experiência estética apurada tal qual Mário Quintana, em "Canção da Chuva e do Vento".

\section{Canção da Chuva e do Vento}


Dança, Velha. Dança. Dança

Põe um pé. Põe outro pé.

Mais depressa. Mais depressa.

Põe mais pé.Pé.Pé.

Upa. Salta. Pula. Agacha.

Mete pé e mete assento.

Que velho agita, frenético,

O seu chicote de vento.

Mansinho agora...mansinho

até de todo caíres...

que o Velho dorme de velho

sob os arcos do Arco-íris.

Mário Quintana

Velha que dança e põe um pé e outro e outro até agitar freneticamente e finalmente de mansinho conseguir ver o arco-íris. É como se os textos "pingassem" aos poucos até formar uma tempestade para então, finalmente, chegar o momento da apreciação e do deleite onde se pode ver o arco-íris, o belo em riqueza de detalhes.

A mediação da professora foi como a dança da Velha, e o agito frenético das ideias que circulavam em sala de aula imitavam o velho a agitar seu chicote de vento. Assim, na situação pedagógica vivida a criação carregou em si a significação das situações pelas crianças, resultando em uma produção imaginária material e simbólica. Esse produto compõe a cultura e passa a ser assumido como imaginário. “[...] é assumido o termo imaginário, [...] para expressar o poder criador do homem e o campo da produção imaginária, cuja matéria prima são as imagens humanas". (PINO, 2006, p. 49).

O imaginário pode ser definido, então, como o ato de criação das imagens. Uma criação no campo da subjetividade, visto que o caráter semiótico das imagens humanas faz 
toda a diferença em relação às imagens naturais do mundo animal. É ele que torna possível o que chamamos de atividade criadora. (PINO, 2006).

Portanto, só é possível entender a criação mediada pelo processo de significação, visto que o imaginário também implica o simbólico. Sem a significação o que nos resta são somente as imagens (pertencente ao campo do natural). Foi no processo de discussão acerca dos textos lidos que a potencialidade de criação dos alunos foi alimentada pela professora e pelos colegas de sala uma vez que o exercício de simbolização das imagens daqueles textos foi realizada conjuntamente pelo grupo. Do texto de Andrade (2003, p. 19), haveriam que entender o que seria "ver no campo dois dragões-da-independência cuspindo fogo e lendo fotonovelas", ou "ver caído no pátio da escola um pedaço de lua, todo cheio de buraquinhos, feito queijo". Ou ainda, "ver todas as borboletas da Terra passando pela chácara de Siá Elpídia formando um tapete voador". Não, tais "mentiras" não mereceriam castigo na opinião dos alunos. Elas deveriam ser tratadas como a possibilidade de "carregar água na peneira" (BARROS, 1999)...

\section{Considerações acerca do imaginário e das possibilidades de criação na escola}

A transformação da natureza pelas mãos humanas é a transformação do real natural como uma categoria abstrata de conceber a realidade - mundo das coisas que têm existência em si - para o real cultural ou real humano (PINO, 2006a), o que pressupõe transformação.

A atividade proposta possibilitou que no movimento interdiscursivo a professora conduzisse seus alunos no caminho da simbolização acerca do real natural transformando-o em real cultural, imaginando possibilidades de criação, porque simbolizaram as imagens que recebiam do mundo externo. A criação, como dita anteriormente, estando no campo do imaginário foi sendo mediada pela leitura dos textos e pela leitura que fizeram à partir dos textos lidos e das experiências vividas. Daí a intrínseca relação entre real, imaginário e simbólico.

Dada a importância de entendermos os processos que envolvem o ato de criação e o lugar do imaginário como condição essencialmente humana, destacamos o papel da escola e as práticas pedagógicas como possibilitadoras de espaços de criação.

A professora instaurou a atividade pela leitura da literatura. Esta, por sua vez, como criação verbal, constitui-se predominantemente de palavras, muitas vezes com uma disposição espacial gráfica - estrofes, capítulos, ilustração etc. São estes elementos significantes que materializam significados e signos, mas "esse objeto da visão estética, possui uma forma espacial interna artisticamente significante que é representada pelas palavras da obra...” (BAKHTIN, 2003, p.108). 
Pela mediação da professora as crianças foram capazes de apreender o objeto estético, a obra de criação verbal, que se produz pela apresentação de coisas do mundo exterior e interior do "cotidiano", "real", relacionadas ao universo fictício sedutor, convincente, prazeroso, fixado pela palavra e sua expressividade, fundamentada internamente pela atividade do autor que constrói tecnicamente o objeto de prazer. Foi quando sugeriram "por que não experimentamos inventar algumas 'mentirinhas', tia?".

No movimento dialógico da aula os alunos produziram compreensões da proposta de um dos colegas - e acatada pelo grupo - daquilo que haviam lido. Compreensões singulares, tributárias de outras compreensões, mediadas por marcadores linguísticos e pelas pistas deixadas nos textos, por seus autores, pelo professor em suas mediações e pelas condições de produção estabelecidas nas relações de ensino.

No acontecimento mesmo da aula a professora foi capaz de sustentar a proposta dos alunos possibilitando uma atividade na qual real e simbólico alimentaram a função criadora do imaginário, o que possibilitou que pelos textos produzidos, e posteriormente ilustrados, os alunos fizessem surgir entes novos, experiências nunca experienciadas, sentimentos nunca sentidos, mundos nunca antes vistos.

\section{Referências:}

ABRAMOVICH, Fanny. Literatura Infantil: gostosuras e bobices, São Paulo: Ed. Scipione, 1994. $172 \mathrm{p}$.

ANDRADE, C. D. de. Contos Plausíveis. 6ª ed. RJ: Record, 2003. 192 p.

BAKHTIN, M.M. Estética da criação verbal. Tradução e introdução de Paulo Bezerra. $4^{\text {a }}$ ed. SP: Martins Fontes, 2003. 512 p.

BARROS, M. de. Exercícios de ser criança. RJ: Salamandra, 1999. 48 p.

DUARTE JÚNIOR, J. F. Por que arte-educação? 6ª ed., Campinas, SP : Papirus, 1991. 88 p.

LIMA, Elvira C. A. S. A Utilização do jogo na pré-escola. In: O jogo e a construção do conhecimento na pré-escola. São Paulo, FDE. Diretoria Técnica. Série Ideias, n. 10, p. 2429, 1992.

PINO, A. A produção imaginária e a formação do sentido estético. Reflexões úteis para uma educação humana. In: Pro-Posições, v. 17, n.2 (50), maio/ago, p. 47-69, 2006. 
Imaginário e Produção Imaginária: Reflexões em Educação. In: DA ROS, S.Z.; MAHEIRIE, K.; ZANELLA, A. V. Relações estéticas, atividade criadora e imaginação: sujeitos e (em) experiência. UFSC. Núcleo de Publicações, Florianópolis, p. 145-155, 2006a.

OMETTO, C. B. C. N; CRISTOFOLETI, R. C. A leitura da literatura como possibilidade de formação. Leitura. Teoria \& Prática, v. 58, p. 1843-1851, 2012.

VIGOTSKI, L.S. Imaginação e criação na infância. São Paulo: Ática, 2009. 136 p. Manuscrito de 1929. In: Educação \& Sociedade, ano XXI, nº 71, Julho, p. 21-44 2000. A formação Social da Mente. 6.ed. São Paulo: Martins Fontes, 1998. 168p.

Recebido em: 24/02/2014

Revisado em: 20/04/2015

Aprovado para publicação em: 23/04/2015

Publicado em: 30/04/2016 